\title{
Screening and Characterization of a Novel RNA Aptamer That Specifically Binds to Human Prostatic Acid Phosphatase and Human Prostate Cancer Cells
}

\author{
Hoon Young Kong ${ }^{1,2}$, and Jonghoe Byun ${ }^{1,2, *}$
}

Prostatic acid phosphatase (PAP) expression increases proportionally with prostate cancer progression, making it useful in prognosticating intermediate to high-risk prostate cancers. A novel ligand that can specifically bind to PAP would be very helpful for guiding prostate cancer therapy. RNA aptamers bind to target molecules with high specificity and have key advantages such as low immunogenicity and easy synthesis. Here, human PAP-specific aptamers were screened from a 2'-fluoropyrimidine (FY)-modified RNA library by SELEX. The candidate aptamer families were identified within six rounds followed by analysis of their sequences and PAP-specific binding. A gel shift assay was used to identify PAP binding aptamers and the $6 \mathrm{~N}$ aptamer specifically bound to PAP with a Kd value of 118 nM. RT-PCR and fluorescence labeling analyses revealed that the $6 \mathrm{~N}$ aptamer bound to PAP-positive mammalian cells, such as PC-3 and LNCaP. IMR-90 negative control cells did not bind the $6 \mathrm{~N}$ aptamer. Systematic minimization analyses revealed that $\mathbf{5 0}$ nucleotide sequences and their two hairpin structures in the 6N 2'-FY RNA aptamer were equally important for PAP binding. Renewed interest in PAP combined with the versatility of RNA aptamers, including conjugation of anti-cancer drugs and nano-imaging probes, could open up a new route for early theragnosis of prostate cancer.

\section{INTRODUCTION}

Prostate cancer (PC) is one of the most common non-skin cancers in men of the Western world and is a second leading cause of cancer death, behind lung cancer (Soares et al., 2013). Compared with other types of cancer, PC grows slowly, and

${ }^{1}$ Department of Molecular Biology, ${ }^{2}$ Institute of Nanosensor and Biotechnology, Dankook University, Yongin 448-701, Korea

*Correspondence: jonghoe@ dankook.ac.kr

Received 11 October, 2014; revised 6 November, 2014; accepted 10 November, 2014; published online 15 January, 2015

Keywords: biomarker, prostate cancer, prostatic acid phosphatase, RNA aptamer early PC often shows no symptoms, which increases the risk of death (Oesterling et al., 1993; Reiter et al., 2013; Wallace et al.,1975). However, use of biomarkers during PC screening and prognostication has revolutionized diagnosis and management of the disease. Some clinically important PC biomarkers include prostate-specific antigen (PSA), prostate-specific membrane antigen, and PAP, which is also known as prostatespecific acid phosphatase. Although PSA has provided significant advances in the diagnosis and prognosis of $\mathrm{PC}$, it has limitations, such as lack of specificity and no safe level that confers a zero risk PC diagnosis (Thomson et al., 2004). Furthermore, PSA is indiscriminately used, which allows for overdiagnosis and over-treatment of low-risk PC that does not affect longevity or quality of life (Walter et al., 2006). These shortcomings have led many researchers to investigate more optimized uses of PSA (Greene et al., 2013) and to develop novel biomarkers (Cary and Cooperberg, 2013).

There is renewed interest in PAP because it is a proportional measure of PC progression and is highly correlated with the morphological characteristics of PC (Azumi et al., 1991; Wang et al., 2005). Strong PAP expression observed in high Gleason score PCs (Gunia et al., 2009) and a cause-specific survival (CSS) study, which tested sera of 193 patients, suggested that PAP is a stronger predictor of CSS than PSA or Gleason score in men with higher risk $\mathrm{PC}$ treated with ${ }^{103} \mathrm{Pd}$ brachytherapy and external beam radiotherapy (Fang et al., 2008). PAP is a significant prognostic factor for patients with intermediate- and highrisk PCs and use of PAP should be reconsidered in these patients. PAP appears to be particularly valuable for predicting distant failure in higher-risk patients for whom high levels of local control have been achieved with initial aggressive local treatment (Taira et al., 2007). PAP was the first serum biomarker used for PC prior to the introduction of PSA, and preoperative PAP levels allowed risk stratification for the likelihood of lymph node-positive disease and the development of metastatic disease (Whitesel et al., 1984). Despite the perceived limitations of PAP as a PC biomarker, such as elevation in patients with non-prostatic disease or benign conditions of the prostate and an artificial setting, it seems timely to re-evaluate the potential utility of PAP.

An aptamer is an oligomer consisting of nucleotides (DNA or RNA) that bind to target molecules with high affinity and specificity. Secondary and tertiary structures of aptamers are impor- 
tant for target binding, specificity, and affinity (Chen et al., 2009; Mosing et al., 2005). In 1990, Szostak's group (Ellington and Szostak, 1990) and Gold's group (Tuerk and Gold, 1990) developed an in vitro aptamer selection process from random sequence pool. Aptamers bind to a wide range of targets, including metal ions (Kawakami et al., 2000), metabolites (Bruno et al., 2008), proteins (Ruckman et al., 1998; Savla et al., 2011), and whole organisms, such as viruses (Tang et al., 2009), bacteria (Hamula et al., 2011) and mammalian cells (Chen et al., 2009). Aptamers have advantages as recognition molecules. First, they can be synthesized chemically, and batch-to-batch variation can be minimized during production. They can also undergo reversible denaturation, making them a very versatile tool for drug loading and antidote applications (Bompiani et al., 2012). Moreover, aptamers elicit little to no immunogenicity in therapeutic applications (Eyetech Study Group, 2002; Foy et al., 2007; Zhu et al., 2012). Furthermore, many functional groups and/or nucleotide extensions can be introduced onto aptamers. Aptamers can be easily conjugated to therapeutic molecules, such as drugs, carriers, toxins, and siRNAs (Liu et al., 2012; Meng et al., 2012; Subramanian et al., 2012; Zhang et al., 2011). Moreover, aptamers can be conjugated with imaging probes for molecular imaging applications (Hong et al, 2011; Song et al., 2013; Talbot et al., 2011; Zhang et al., 2012).

Here, we generated an RNA aptamer against PAP using an in vitro selection method employing 2'-fluoropyrimidine (FY)modified RNA, which helps increase RNA stability in biological fluids. The selected RNA aptamer was characterized for binding specificity followed by minimization. The binding region was identified using truncated versions of the RNA aptamer. The results suggest that 50 nucleotide sequences and their two hairpin structures are important for PAP binding. Together with specific binding to PAP-expressing PC cells, these aptamer data should have implications for early theragnosis of PC based on RNA ligands.

\section{MATERIALS AND METHODS}

\section{Animal cell culture}

Human prostate cancer (PC) cells, PC-3 (CRL-1435, ATCC) and LNCaP (CRL-1740, ATCC), were cultured in RPMI-1640 (Welgene, Korea) medium containing $10 \%(\mathrm{v} / \mathrm{v})$ fetal bovine serum (Welgene, Korea) and $1 \%(\mathrm{v} / \mathrm{v})$ penicillin/streptomycin (Welgene, Korea) at $37^{\circ} \mathrm{C}$ in a humidified $5 \% \mathrm{CO}_{2}$ atmosphere. Human normal lung fibroblast, IMR-90 (CCL-186), was maintained in Eagle's Minimum Essential Medium (Welgene, Korea) supplemented with $10 \%(\mathrm{v} / \mathrm{v})$ fetal bovine serum (Welgene, Korea) and $1 \%(\mathrm{v} / \mathrm{v})$ penicillin/streptomycin (Welgene, Korea) at $37^{\circ} \mathrm{C}$ in a humidified $5 \% \mathrm{CO}_{2}$ atmosphere.

\section{Cloning and expression of PAP}

The total RNA isolated from PC3 cells by TRIzol (Invitrogen, USA) was reverse transcribed with oligo(dT) ${ }_{18}$ primer and $M-$ MuLV reverse transcriptase (Enzynomics, Korea). The cDNA was then amplified by PCR with hPAP-F primer (5'-CGGGATCCAAGGAGTTGAAGTTTGTGACTTTG-3') and hPAP-R primer (5'-CCCAAGCTTTTGATGGCTGTTTGTGGTC-3') to clone extracellular domain of human PAP. The PCR consisted of 35 cycles of denaturation $\left(95^{\circ} \mathrm{C}\right.$ for $\left.30 \mathrm{~s}\right)$, annealing $\left(58^{\circ} \mathrm{C}\right.$ for $30 \mathrm{~s})$, and extension $\left(72^{\circ} \mathrm{C}\right.$ for $\left.30 \mathrm{~s}\right)$. The resulting fragment was cloned into $\mathrm{pQE}-80 \mathrm{~L}$ vector (Qiagen, USA) and expressed in Origami strain (Novagen, USA) for protein purification.

Protein purification

Overnight cultures of transformed E.coli were inoculated 1:100 into Luria-Bertani media and grown with shaking at $37^{\circ} \mathrm{C}$ to purify the His-tagged PAP fusion proteins. Isopropyl $\beta$-D-thiogalactopyranoside was added at a final concentration of $0.2 \mathrm{mM}$ when a culture optical density $(600 \mathrm{~nm})$ of 0.5 was reached, and the cultures were grown at $30^{\circ} \mathrm{C}$ for $4 \mathrm{~h}$. After induction, the cells were harvested, frozen at $-80^{\circ} \mathrm{C}$ for $16 \mathrm{~h}$, thawed, and resuspended in $20 \mathrm{ml}$ lysis buffer $\left(50 \mathrm{mM} \mathrm{NaH}_{2} \mathrm{PO}_{4}(\mathrm{pH} 8.0)\right.$, $0.3 \mathrm{M} \mathrm{NaCl}, 10 \mathrm{mM}$ imidazole, $20 \mathrm{mM} \beta$-mercaptoethanol, $0.5 \%(\mathrm{v} / \mathrm{v})$ sarkosyl) containing lysozyme $(2.5 \mathrm{mg} / \mathrm{ml})$ followed by sonication. After centrifugation at $13,000 \mathrm{rpm}$ for $30 \mathrm{~min}$, the supernatant containing PAP protein was mixed with Ni-IDA silica beads (Macherey-Nagel) and incubated with shaking for 3 $\mathrm{h}$ at $4^{\circ} \mathrm{C}$. Then the pelleted Ni-IDA silica beads were washed twice with the lysis buffer and eluted with two consecutive loading of $1.5 \mathrm{ml}$ elution buffer (50 mM NaH $\mathrm{PO}_{4}(\mathrm{pH} 8.0), 0.3 \mathrm{M}$ $\mathrm{NaCl}, 10,20,50,100 \mathrm{mM}$ imidazole). All eluates were dialyzed extensively against PBS and the concentrations determined by the Bradford assay (Bio-rad, USA).

Preparation of 2'- fluoropyrimidine (FY) modified RNA library and in vitro transcription

The starting DNA library was synthesized from Bionics (Korea). DNA library contained 40 nucleotides of random sequences $\left(\mathrm{N}_{40}\right)$ which were flanked by constant regions. PCR was performed with Sel-5' primer (5'-GGTAATACGACTCACTATAGGGAGAGCGGAAGCGTGCTGGG-3') and Sel-3' primer (5'GGGGGGATCCATCGACCTCTGGGTTATG-3') and the resulting single-stranded DNA library was used as a template for in vitro transcription. The PCR conditions were same as above except that the cycle was repeated for 10 times. Five hundred nanogram of each PCR product was used as a template for in vitro transcription. To generate 2'-fluoropyrimidine RNA, DuraScribe $^{\mathrm{TM}}$ (Epicentre, USA) was used following the manufacturer's instructions. Briefly, $5 \mathrm{mM}$ of ATP, GTP, 2'-fluorine-dCTP and 2'-fluorine-dUTP (provided in the kit) were used for in vitro transcription. After incubating at $37^{\circ} \mathrm{C}$ for $16 \mathrm{~h}$, the reaction mixtures were subjected to denaturing urea polyacrylamide gel electrophoresis (7 M urea, $8 \%(\mathrm{w} / \mathrm{v})$ polyacrylamide, $1 \mathrm{X}$ TBE) to separate residual NTPs. Transcribed RNA was eluted in the TE buffer (10 mM Tris-HCl, pH 8.0, 1 mM EDTA, pH 8.0) for $16 \mathrm{~h}$ at $37^{\circ} \mathrm{C}$. A four-fold excess of $5^{\prime}$-end biotin-modified GMP (4 $\mathrm{mM}$ ) compared to that of GTP $(1 \mathrm{mM})$ was added to the reaction mixture for in vitro transcription of $5^{\prime}$-end biotinylated 2'-FY RNA. The DuraScribe ${ }^{\mathrm{TM}}$ kit was used for in vitro transcription.

\section{In vitro selection of RNA aptamers}

The systematic evolution of ligands by exponential enrichment (SELEX) was performed as described (Gopinath, 2007). RNA pools were heated to $95^{\circ} \mathrm{C}$ for 5 min during every round, and then slowly cooled to room temperature for refolding of RNA. The initial 210 pmol of the RNA pool was pre-cleared with $\mathrm{Ni}$ IDA silica beads in binding buffer (30 mM Tris- $\mathrm{HCl}, \mathrm{pH} 7.5,150$ $\mathrm{mM} \mathrm{NaCl}, 1.5 \mathrm{mM} \mathrm{MgCl}$, $2 \mathrm{mM}$ DTT, $1 \%$ (w/v) BSA) for 20 min for the first round of selection. Then, target protein (105 pmol) was added to the pre-cleared RNA pool and incubated for $20 \mathrm{~min}$. Subsequently, fresh Ni-IDA silica beads were added and incubated for an additional $20 \mathrm{~min}$. The bead bound protein-RNA complexes were separated with a quick spin minicentrifuge for $30 \mathrm{~s}$. After 5 times of washing with binding buffer, the bound RNA was eluted by phenol/chloroform extraction. The recovered RNA pool was reverse transcribed and amplified by 20 cycles of PCR. From the second to the sixth rounds, the amounts of RNA and target protein added were $150 \mathrm{pmol}$ and 75 pmol, respectively. Competitor tRNA was added beginning 
in the fourth round to increase the stringency of aptamer selection. After the six rounds, the amplified cDNAs were cloned into TA-cloning vector (Solgent, Korea) followed by sequencing and 2D structure analysis using the Mfold program (Zuker, 2003).

\section{Real-time RT-PCR analysis of aptamer-PAP binding} Thirty pmole of PAP was incubated with 300 fmole of RNA aptamer in binding buffer for $20 \mathrm{~min}$ at room temperature. Subsequently, fresh Ni-IDA silica bead (MN, Germany) was added for binding of protein-RNA aptamer complex. After a $20 \mathrm{~min}$ incubation with occasional inversion, the unbound RNA aptamer was washed out. The bound RNA aptamer was recovered by phenol extraction and ethanol precipitation followed by reverse transcription for real-time PCR analysis by Rotor-Gene 6000 (Corbett, USA) and SYBR Green I dye. Known amounts of the RNA aptamer $(1,000 \mathrm{pg}, 100 \mathrm{pg}$, and $10 \mathrm{pg})$ were used as real-time PCR standards. The PCR conditions were same as above and run for 40 cycles. The library RNA served as a negative control.

\section{Electrophoretic mobility shift assay (EMSA)}

Twelve pmole of PAP was mixed with 60 fmole of each RNA aptamer and 20 pmole of yeast tRNA (Sigma, USA) in EMSA binding buffer (30 mM Tris-Cl, pH 7.5, $150 \mathrm{mM} \mathrm{NaCl}, 1.5 \mathrm{mM}$ $\mathrm{MgCl}_{2}, 2 \mathrm{mM}$ DTT) and incubated for $20 \mathrm{~min}$ at room temperature. The reaction mixture was electrophoresed on an $8 \%(\mathrm{w} / \mathrm{v})$ non-denaturing polyacrylamide gel (1X TBE, $10 \mathrm{mM} \mathrm{MgCl}_{2}, 2 \%$ (v/v) glycerol) at $4^{\circ} \mathrm{C}$. The bands were detected by Ambion Bright Star BioDetected Kit according to the manufacturer's instructions. Briefly, the separated RNA aptamer was transferred to the nylon membrane for $1 \mathrm{~h}$ at $200 \mathrm{~mA}$ followed by UV crosslinking, blocking with the buffer provided in the kit, and hybridization with 5'-biotinylated probe (5'-CGCGGCCTTTACTCACG-3'). After washing, streptavidin-AP conjugate was added, and substrate (CDP-star) was treated for visualization of bands. When the 5'-biotin labeled RNA aptamer was used, treatment of biotinylated probe was omitted. For in vitro competition assay, twelve pmol of PAP and 60 pmol of biotinylated RNA aptamer and unlabeled RNA aptamer were incubated in binding buffer at room temperature for $20 \mathrm{~min}$. The amount of unlabeled RNA aptamer was increased from $0 \mathrm{pmol}$ to $600 \mathrm{pmol}(0,1,2,5$, and 10-fold). The library RNA was used as a negative control and Northern blot analysis was performed as described above.

\section{Mammalian cell binding assay}

PC-3, LNCaP and IMP-90 cells were seeded in $35 \mathrm{~mm}$ cell culture dish with corresponding medium and grown up to $90 \%$ confluence. The cells were treated with 10 pmol of $6 \mathrm{~N}$ RNA aptamer or library RNA for $20 \mathrm{~min}$ at $37^{\circ} \mathrm{C}$. After washing three times with PBS containing 0 or $150 \mathrm{mM} \mathrm{NaCl}$ for $5 \mathrm{~min}$, total RNA was isolated with TRI reagent (MRC, USA). The obtained RNA was reverse transcribed with M-MuLV reverse transcriptase (Enzynomics, Korea) and the resulting cDNA was used for PCR reaction. In reverse transcription, Sel-3' primer was used to detect aptamer whereas oligo (dT) 18 primer was used to estimate the level of GAPDH and prostatic acid phosphatase. In aptamer detection, Mini-1-F primer (5'-GGTAATACGACTCACTATAGGGCTGTGTGAGAG-3') was used together with the Sel-3' primer. The PCR consisted of 35 cycles of denaturation $\left(95^{\circ} \mathrm{C}\right.$ for $\left.30 \mathrm{~s}\right)$, annealing $\left(63^{\circ} \mathrm{C}\right.$ for $30 \mathrm{~s}[\mathrm{hPAP}]$ or $66.3^{\circ} \mathrm{C}$ for $30 \mathrm{~s}$ [aptamer]), and extension $\left(72^{\circ} \mathrm{C}\right.$ for $\left.30 \mathrm{~s}\right)$.

Aptamer-based fluorescence assay

To amplify the fluorescence of RNA aptamer signal, tyramide signal amplification (TSA ${ }^{\mathrm{TM}}$, PerkinElmer, USA) was used following the manufacturer's instructions. Briefly, PC-3 and LNCaP cells were grown up to $80 \%$ confluence on cover slide, followed by washing with PBS and fixing with $4 \%(\mathrm{w} / \mathrm{v})$ paraformaldehyde for $20 \mathrm{~min}$. Then, the cells were washed 3 times with M-PBS (PBS including $15 \mathrm{mM} \mathrm{MgCl}$ ) and treated with quenching solution ( $3 \%(\mathrm{v} / \mathrm{v}) \mathrm{H}_{2} \mathrm{O}_{2}, 15 \mathrm{mM} \mathrm{MgCl} 2$ in PBS) for $20 \mathrm{~min}$. The quenched cells were blocked with blocking buffer (provided in the kit, TNB buffer) for $30 \mathrm{~min}$ at room temperature, treated with aptamer or library RNA for $20 \mathrm{~min}$ at room temperature $(20 \mathrm{pmol})$, and washed 3 times with M-PBS to remove unbound RNA aptamers. Then, 5'-biotinylated probe (20 pmol) was treated for $20 \mathrm{~min}$ at room temperature followed by hybridization with HRP-streptavidin (1:100 dilution) for $20 \mathrm{~min}$ at room temperature. The cells were then washed three times with M-PBS followed by treatment of TSA-Cy3 (prediluted 50fold in amplification solution provided in the kit) for $5 \mathrm{~min}$ at room temperature. The cells were mounted with Slowfade gold antifade reagent with DAPI (Invitrogen, USA) and fluorescence images were captured using confocal laser scanning microscopy (Carl Zeiss LSM710, Germany).

Minimization of 6N RNA aptamer

To synthesize the template for minimization of aptamer, primer dimer was generated by PCR and this was used as a template for in vitro transcription. Mini-1-M primer (5'-GGGCTGTGTGAGAGCCGTGAGTAAAAGGCCGCGAC-3') and Mini-1-F primer was used to get $6 \mathrm{~N}$-pM1 DNA (partial minimization version 1). Mini-1-R primer (5'-TAAAAGGCCGCGACAAAGATCGGACATAACCC-3') and Mini-1-F primer together with 6N-pM1 DNA were used to synthesize template for 6N-M1 RNA aptamer. Mini-2-F (5'-GGTAATACGACTCACTATAGGGTGTGTGAGAGCCGTGAGTAAA-3') and Mini-2-R (5'-GAGAGCCGTGAGTAAAAGGCCGCGACAAAGATCGGACATACC-3') primer set, Mini-3-F (5'-GGTAATACGACTCACTATAGGGAGCCGTGAGTA-AA-3') and Mini-3-R (5'-GGGAGCCGTGAGTAAAAGGCCGCGACAAAGATCCC-3') primer set, and Mini-4-F (5'GGTAATACGACTCACTATAGGGCGTGAGTA-3') and Mini-4R (5'-TATAGGGCGTGAGTAAAAGGCCGCG-3') primer set were used for template of $6 \mathrm{~N}-\mathrm{M} 2,6 \mathrm{~N}-\mathrm{M} 3$ and $6 \mathrm{~N}-\mathrm{M} 4 \mathrm{RNA}$ aptamers, respectively. The PCR consisted of 35 cycles of denaturation $\left(95^{\circ} \mathrm{C}\right.$ for $\left.30 \mathrm{~s}\right)$, annealing $\left(55^{\circ} \mathrm{C}\right.$ for $30 \mathrm{~s}[6 \mathrm{~N}-\mathrm{pM} 1$, $6 \mathrm{~N}-\mathrm{M} 2,6 \mathrm{~N}-\mathrm{M} 3$ and $6 \mathrm{~N}-\mathrm{M} 4$ ] or $68.4^{\circ} \mathrm{C}$ for $30 \mathrm{~s}$ [6N-M1]), and extension $\left(72^{\circ} \mathrm{C}\right.$ for $\left.30 \mathrm{~s}\right)$. The templates for in vitro transcription of truncated versions of $6 \mathrm{~N}-\mathrm{M} 2 \mathrm{RNA}$ aptamer $(6 \mathrm{~N}-\mathrm{M} 2-\mathrm{RD}$, 6N-M2-TD and 6N-M2-RTD) were generated by using 6N-M2RD-F (5'-GGTAATACGACTCACTATAGGGTGTGTGATAGCCGTG-3') and 6N-M2-RD-R (5'-GTGTGTGATAGCCGTGAGTAAAAGGCCTCGGACATACC-3') primer set, 6N-M2-TD-F (5'-GGTAATACGACTCACTATAGGGTGTGTGAGAGCCGC$3^{\prime}$ ) and 6N-M2-TD-R (5'-GGTGTGTGAGAGCCGCGGCAAAGACCGGAACATACCC-3') primer set, 6N-M2-RTD-F (5'GGTAATACGACTCACTATAGGGTGTGTGAGA-3') and 6NM2-RTD-R (5'-TATAGGGTGTGTGAGAGCCGCGGACATACCC-3') primer set, respectively. The PCR conditions were same as above except that different setting $\left(55^{\circ} \mathrm{C}\right.$ for $\left.30 \mathrm{~s}\right)$ was used for annealing. The DuraScribe ${ }^{\mathrm{TM}}$ kit was used for in vitro transcription.

\section{RESULTS}

RNA aptamer selection against the extracellular domain of human prostatic acid phosphatase (rhecdPAP)

The extracellular domain (187A to 1227A, NM_001099.4) of the 
A

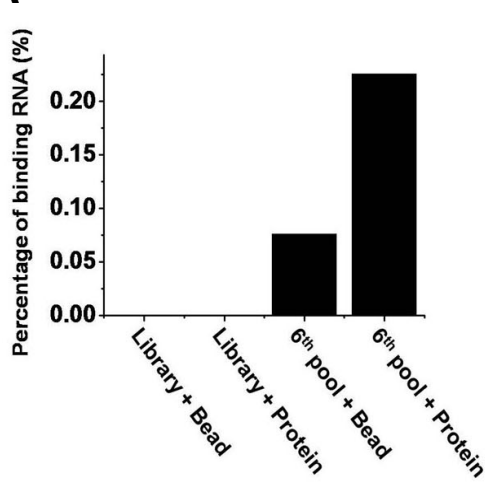

B

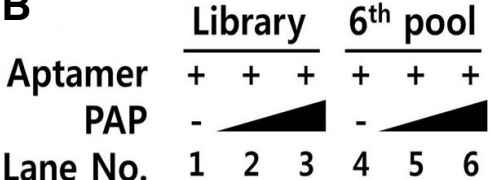

Lane No. $\begin{array}{lllllll}1 & 2 & 3 & 4 & 5 & 6\end{array}$

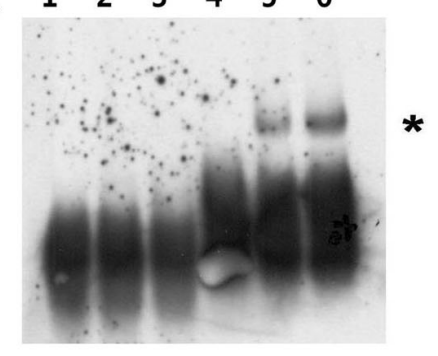

C

Group I
8
12
$2 N$
2
$3 N$
2 ON
10
Group II
7
$11 N$
13
9
11
NON-GrOUP
$1 N$
$6 N$
$19 N$
$21 N$
$24 N$

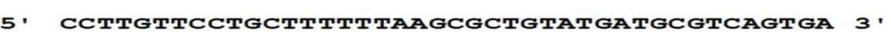

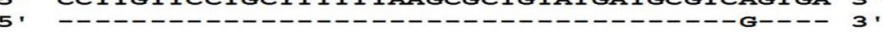

5. T-

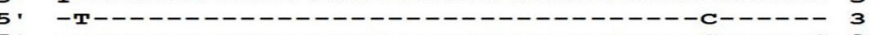

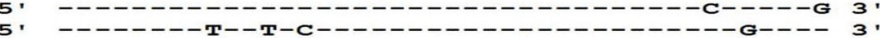

5. ССTGTTTTTAAGCACTGTATGATGTGTGGCCGCСTTATTCGT 3

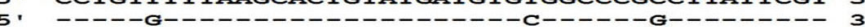

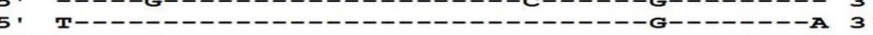

5.

5. CCAGCGGTGGTGGATCGAATAGTTCAGTACTAGGCCAGAGCA 3

5. CTGTGTGAGAGCCGTGAGTAAAAGGCCGCGACAAAGATCGGA 3

5. TCGTGTGAGAGCCGTAAGTGAAAGGCCGCGACAAAGATCGGA 3

5. CCCTTAAGGGGGAACGCATTGTTGCGTTCTATCСTCTCAGTA 3
5. -
Fig. 1. The sixth RNA pool that binds prostatic acid phosphatase (PAP) was enriched. (A) After six rounds of SELEX, the RNA ligands that bound PAP were enriched 3.52-fold using real-time RTPCR. (B) The electrophoretic mobility shift assay (EMSA) results showed that the sixth RNA pool bound to the target proteins in a concentration-dependent manner compared to that of library. (C) Seventeen RNA aptamer candidates were obtained after a cloning and sequence analysis of the sixth RNA pool. These RNA aptamer candidates were classified into three groups according to their sequence similarities (Group I, Group II, and NonGroup). Identical nucleotides are represented as a line. human prostatic acid phosphatase (PAP) protein was chosen as the target because the catalytic site (active site) is located in the extracellular space. The cloned cDNA sequence (Supplementary Fig. S1) indicated that the PAP clone was authentic PAP with the same amino acid sequence as the reported sequence (Supplementary Fig. S2). To select RNA aptamers against this extracellular domain of human PAP, six systematic evolution of ligands by exponential enrichment (SELEX) procedure rounds were performed. A significant increase in total binding of the round 6 RNA pool (pool 6) was observed compared to that in the initial RNA library, as measured by real-time quantitative RT-PCR and Electrophoretic mobility shift assay (EMSA) (Figs. 1A and 1B), indicating that the binding RNAs were enriched. To analyze the binding RNAs, the sixth RNA pool was amplified by RT-PCR and the resulting products were cloned into the pT-blunt vector. Seventeen clones were isolated, and their sequences were analyzed. The clones were classified into Group I, Group II, and Non-Group based on the sequence similarities of random sequence regions (Fig. 1C).

\section{2'-FY RNA aptamer clones bind to PAP}

To generate a nuclease-resistant RNA aptamer, transcription was performed using the 2'-FY RNA. The most representative RNA aptamers from each group (12 from Group I, $11 \mathrm{~N}$ from Group II, and 19N from Non-Group) were chosen and evaluated for target binding capability using the EMSA. Although $11 \mathrm{~N}$ and 12 bound to PAP (RNA-protein complexes are marked with an asterisk), 19 from the Non-Group did not bind to PAP (Fig. 2A, lanes 4, 6, and 8). The EMSA was extended to all aptamers to confirm the binding ability of the clones that belong to each group. As shown in Figs. $2 \mathrm{~A}$ and $2 \mathrm{~B}$, only clone 12 in Group I bound to PAP. Clones $11 \mathrm{~N}$ and 13 in Group II bound to the target protein (Fig. 2C, lanes 4 and 12). The NonGroup clones $1 \mathrm{~N}, 6 \mathrm{~N}$, and $24 \mathrm{~N}$ also bound to PAP (Fig. 2D, lanes 4, 6 and 12). The apparent band intensities of the RNA aptamer-protein complexes suggested that the clones $11 \mathrm{~N}$ and $6 \mathrm{~N}$ bound more strongly to PAP than $12,13,1 \mathrm{~N}$ and $24 \mathrm{~N}$ clones. To estimate binding capability of the $11 \mathrm{~N}$ and $6 \mathrm{~N}$ RNA aptamers, real-time RT-PCR was performed (Fig. 2E). The result showed that the 6N RNA aptamer bound to PAP with approximately three-fold higher affinity than that of the $11 \mathrm{~N}$ RNA aptamer ( $\%$ of input: $11 \mathrm{~N}=2.26 \%$ vs. $6 \mathrm{~N}=6.14 \%$ ). These results indicate that the 6N RNA aptamer has better target binding capability than others $(12,13,1 \mathrm{~N}, 11 \mathrm{~N}$, and $24 \mathrm{~N})$.

The 6N 2'-FY RNA aptamer specifically binds to PAP

The $5^{\prime}$-end of the $6 \mathrm{~N} 2^{\prime}-\mathrm{FY}$ RNA aptamer was biotinylated to confirm specific binding of the $6 \mathrm{~N} 2^{\prime}-\mathrm{FY}$ RNA aptamer to PAP; thus, generating the B-6N 2'-FY RNA aptamer, which was used for a dose-dependent binding test and in vitro competition assay. As shown in the EMSA result (Fig. 3A, lanes 2-10), the B$6 \mathrm{~N} 2$ '-FY RNA aptamer successfully bound to PAP in a dosedependent manner. Furthermore, an increasing amount of unlabeled $6 \mathrm{~N}$ 2'-FY RNA aptamer in the competition assay effectively inhibited the B-6N 2'-FY RNA aptamer-PAP interaction in a dose-dependent manner (Fig. 3B, lanes 2 and 7-10). In contrast, the unlabeled library 2'-FY RNA did not show any competitive inhibition (Fig. 3B, lanes 2-6). These results dem- 


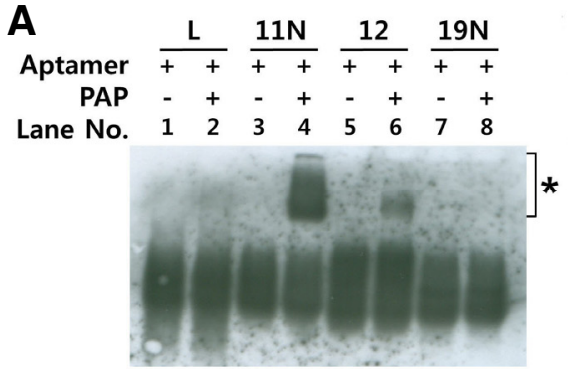

C

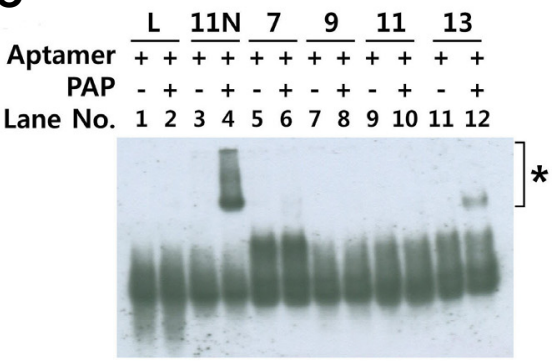

B

Aptamer $\frac{\mathrm{L}}{+++} \frac{2}{+++\frac{10}{++}} \frac{2 \mathrm{~N}}{++} \frac{3 \mathrm{~N}}{++\frac{2 O N}{++}}$

PAP - + - + + - + - + + - +

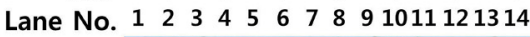

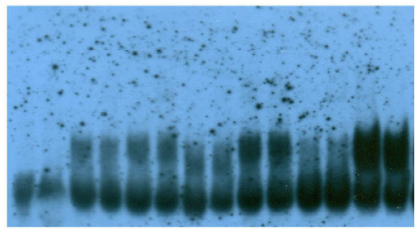

D

Aptamer $\frac{\mathrm{L}}{++} \frac{1 \mathrm{~N}}{++} \frac{6 \mathrm{~N}}{++\frac{19 \mathrm{~N}}{++}} \frac{21 \mathrm{~N}}{++\frac{24 \mathrm{~N}}{++}}$

PAP - + - + + - + - + - +

Lane No. $1 \begin{array}{llllllllllll}1 & 2 & 3 & 4 & 5 & 6 & 7 & 8 & 9 & 10 & 11 & 12\end{array}$
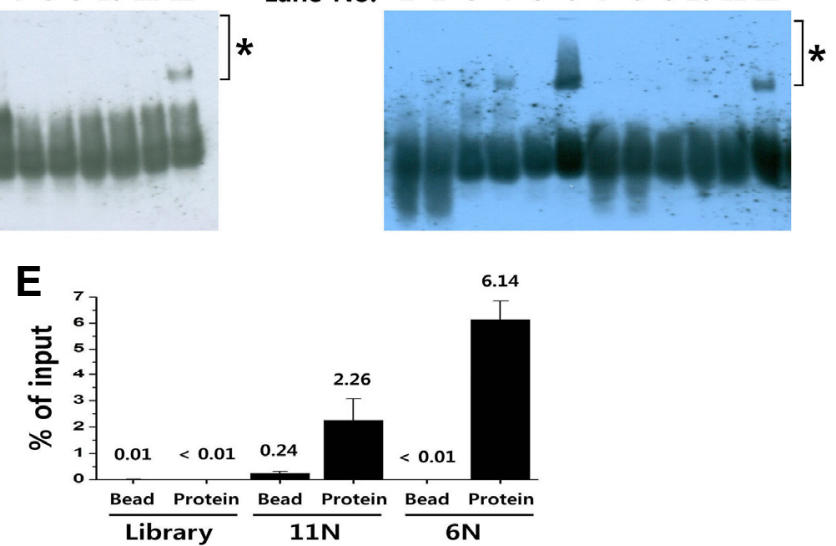

A

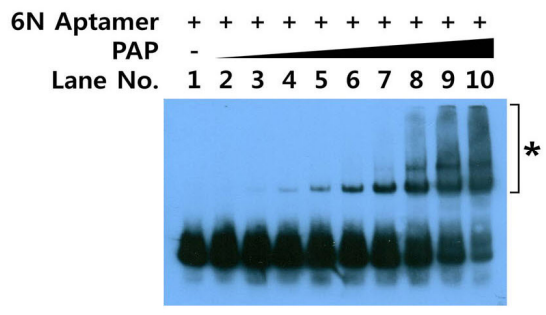

B

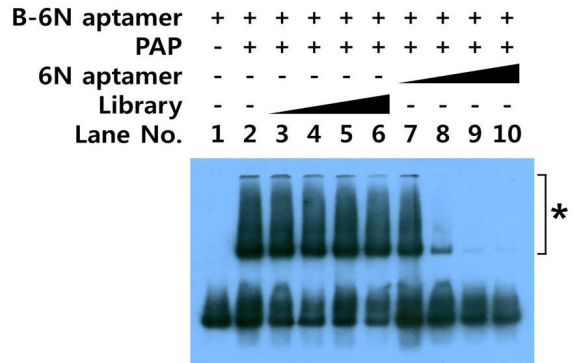

Fig. 2. The $6 \mathrm{~N}$ RNA aptamer has the best target binding capacity among the six RNA aptamers. A binding assay was performed to determine which RNA aptamer candidates bound to PAP. (A) The EMSA results of representative RNA aptamers from each group (Group I: 12, Group II: $11 \mathrm{~N}$, and Non-Group: 19N). (B) The EMSA result of the Group I aptamer candidates (clone 12 was excluded). (C) The EMSA result of the Group II aptamer candidates. (D) The EMSA result of the Non-Group aptamer candidates. (E) Two aptamer candidates ( $11 \mathrm{~N}$ and $6 \mathrm{~N}$ ) showed strong binding and were analyzed for their binding percentage using real-time RTPCR $(2.26 \%$ and $6.14 \%$, respectively).

Fig. 3. The $6 N 2$ '-fluoropyrimidine (FY) RNA aptamer specifically binds to PAP. (A) $6 N 22^{\prime} F Y$ RNA aptamer binding to PAP increased in a dosedependent manner (RNA: protein $=1: 0,4,8,16,32,64,128,256,512$, and 1024). The 5'-biotinylated end of the $6 \mathrm{~N} 2{ }^{\prime}-\mathrm{FY}$ RNA aptamer was used. (B) Competitive binding assay of the 6N 2'-FY RNA aptamer. The unlabeled 2'-FY RNA library did not affect binding of the biotinylated 6N 2'-FY RNA aptamer (lanes 3-6, B-6N aptamer: library RNA = 1: 1, 2, 5 and 10, respectively). However, the unlabeled 6N 2'-FY RNA aptamer (6N aptamer) competitively disrupted the B-6N 2'-FY RNA aptamer-PAP interaction (lanes 7-10, B-6N aptamer: 6N aptamer = 1: 1, 2, 5 and 10, respectively). The B-6N 2'-FY RNA aptamer:PAP ratio was 1:200 (lanes 2-10). (C) Real-time RT-PCR assay determined that binding affinity $(\mathrm{Kd})$ of the $6 \mathrm{~N} 2^{\prime}-\mathrm{FY}$ RNA aptamer was approximately $118 \mathrm{nM}$.

onstrate that the $6 \mathrm{~N} 2^{\prime}-\mathrm{FY}$ RNA aptamer specifically bound to PAP. The binding affinity (Kd value) of the $6 \mathrm{~N} 2$ '-FY RNA aptamer was $118 \mathrm{nM}$ by real-time RT-PCR (Fig. 3C).

The 6N 2'-FY RNA aptamer binds to PAP-expressing PC cells

The $6 \mathrm{~N} 2$ '-FY RNA aptamer was added to the cells, and its binding was analyzed by RT-PCR to examine whether the $6 \mathrm{~N}$
2'-FY RNA aptamer against the rhecdPAP could bind naive human PAP expressing cells such as PC-3 (human prostatic adenocarcinoma) and LNCaP (human prostatic carcinoma). The PC-3 and LNCaP cells expressed PAP (Fig. 4, rows 2 and 5), whereas IMR-90 (human normal lung fibroblast) cells, which were used as a negative control, did not express PAP (Fig. 4, row 8). Washing with PBS or PBS containing $150 \mathrm{mM} \mathrm{NaCl}$ did not affect PAP mRNA levels (Fig. 4, lanes 1-3). Non-specific 


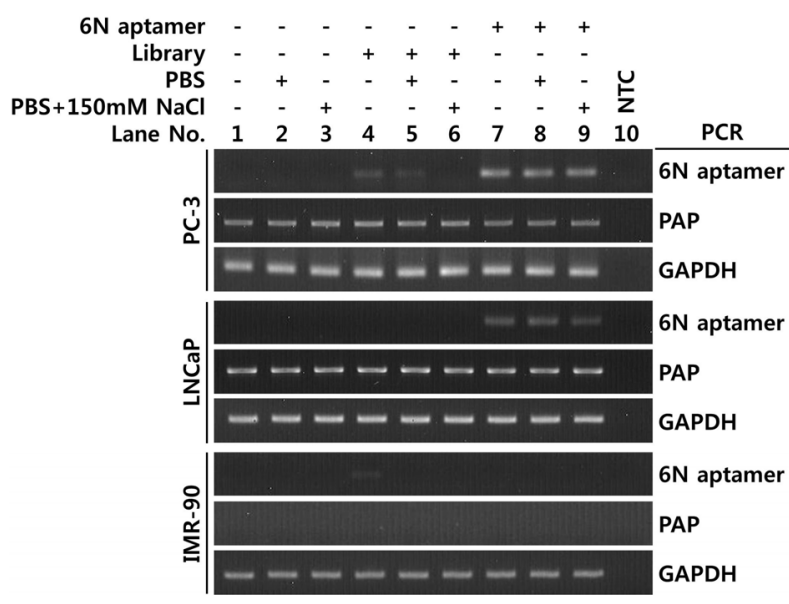

Fig. 4. $6 \mathrm{~N} 22^{\prime}-\mathrm{FY}$ RNA aptamer binding assay in the PAPexpressing prostate cancer cells. A mammalian cell binding test was performed to explore $6 \mathrm{~N}$ 2'-FY RNA aptamer binding to PAPpositive cells. PAP expression was observed in prostate cancer cells (PC-3, 2nd row and LNCaP, 5th row). However, normal lung fibroblast cell (IMR-90) did not express PAP (8th row). Mock (lanes 1-3), 2'-FY RNA library (lanes 4-6) and the 6N 2'-FY RNA aptamer (lanes 7-9) were added to mammalian cells. The aptamer bands were detected by RT-PCR assay after not washing (lanes 1, 4 and 7) or washing with PBS (lanes 2, 5 and 8) or PBS containing 150 $\mathrm{mM} \mathrm{NaCl}$ (PBS + $150 \mathrm{mM} \mathrm{NaCl}$, lanes 3, 6, and 9). Non-specific library RNA binding was detected in the no washed and/or PBS washed groups (1st and 7nd row). However, non-specific binding was completely eliminated by washing with PBS containing 150 $\mathrm{mM} \mathrm{NaCl}$ (lane 6). In contrast, binding of the 6N 2'-FY RNA aptamer was maintained in the aptamer-treated group (lanes 7-9), (first, fourth and seventh rows). NTC : non template control.

RNA binding was observed in the PC-3 library-treated group (Fig. 4, lane 4), which was partially or completely eliminated by washing with PBS or PBS containing $150 \mathrm{mM} \mathrm{NaCl}$ (Fig. 4, lanes 5 and 6). The band corresponding to the $6 \mathrm{~N} 2^{\prime}-\mathrm{FY}$ RNA aptamer was detected only in PC-3 and LNCaP cells (Fig. 4, rows 1 and 4), but not in PAP-negative cells (IMR-90) (Fig. 4, row 7). $6 \mathrm{~N}$ 2'-FY RNA aptamer binding was not eliminated by washing with PBS or PBS containing $150 \mathrm{mM} \mathrm{NaCl}$. These results demonstrate that the $6 \mathrm{~N} 2$ '-FY RNA aptamer can bind only to PAP-expressing PC cells.

The 6N 2'-FY RNA aptamer is localized on cell membrane regions of PAP-positive PC cells

Next, 6N 2'-FY RNA aptamer binding to PC-3 and LNCaP cells was examined by amplifying the aptamer signal using fluorescence. Fluorescence signals were detected only in the $6 \mathrm{~N} \mathrm{2'-}$ FY RNA aptamer-treated groups compared to that in the probe and library control groups (Fig. 5). Interestingly, fluorescence signals were observed only in cell membrane regions, suggesting that the $6 \mathrm{~N} 2$ '-FY RNA aptamer binds to membrane regions of $P C$ cells without being internalized.

A 50 nucleotide sequence in the 6N 2'-FY RNA aptamer appears to be essential for PAP binding

The 6N 2'-FY RNA aptamer is 92 nucleotides in length. However, RNA aptamer size should be $<60$ nucleotides for cost-
PC-3

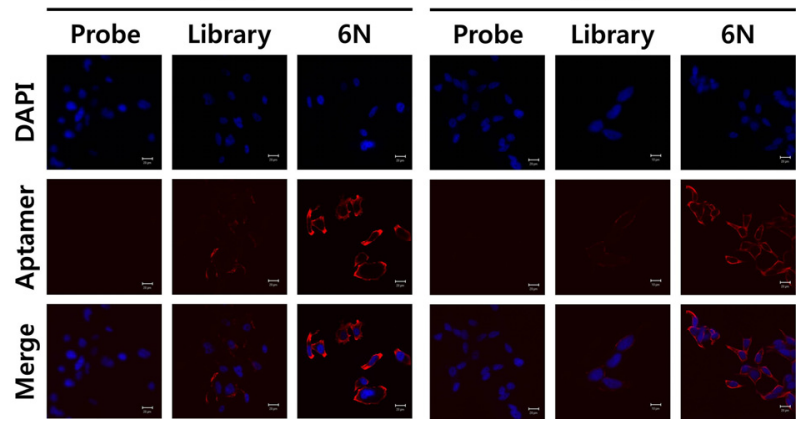

Fig. 5. The $6 \mathrm{~N} 2$ '-FY RNA aptamer binds to PAP-expressing prostate cancer cells. An aptamer-based fluorescence assay was performed to confirm binding of the $6 \mathrm{~N}$ 2'-FY RNA aptamers to PAPpositive cells. No non-specific binding was observed in the biotinylated probe treated group (first column for each cell type). Strong binding was observed in the $6 \mathrm{~N} 22^{\prime}-\mathrm{FY}$ RNA aptamer group in both PC-3 and LNCaP cells (3rd column of each cells) compared with little binding in the library group (second column for each cell type). Tyramide signal amplification (TSA ${ }^{\mathrm{TM}}$ ) was used (red: aptamerbiotinylated probe-straptavidin-HRP-TSA-Cy3 complex; blue: DAPI stained indicating the nucleus) to amplify the aptamer fluorescence signals. All images were captured using confocal laser scanning microscopy. Twenty pmol of the RNA aptamer and a 5'-end biotinylated probe were used.

effectiveness of the chemical synthesis. Moreover, this size minimization approach must not affect target binding capacity. The secondary structures of the $6 \mathrm{~N} 2^{\prime}-\mathrm{FY}$ RNA aptamer were predicted using M-fold software, and two different structures of the full length $6 \mathrm{~N} 2$ '-FY RNA aptamer were obtained (Figs. 6A and $6 \mathrm{~B}$ ). A minimization scheme was developed based on these structures, considering the random sequences (marked with yellow background) and bulges. Four truncated versions (6N-M1, 6N-M2, 6N-M3, and 6N-M4) were generated and investigated. Interestingly, $6 \mathrm{~N}-\mathrm{M} 1$ and $6 \mathrm{~N}-\mathrm{M} 2$ had two different secondary structures (L-shape and $Y$-shape in Figs. $6 \mathrm{~A}$ and $6 \mathrm{~B}$, respectively), whereas $6 \mathrm{~N}-\mathrm{M} 3$ and $6 \mathrm{~N}-\mathrm{M} 4$ had only one non- $\mathrm{Y}$ shaped structure. Next, binding capacity of each minimized version was examined using the gel shift assay (Fig. 6C). Only 6N-M1 and 6N-M2 retained the ability to bind to PAP (Fig. 6C, lanes 4 and 6). $6 \mathrm{~N}-\mathrm{M} 3$ and $6 \mathrm{~N}-\mathrm{M} 4$ lost binding upon minimization (Fig. 6, lanes 8 and 10). Densitometric analysis indicated that $25.8 \%$ of $6 \mathrm{~N}$ RNA aptamer bound to PAP (lane 2), whereas the portions of $6 \mathrm{~N}-\mathrm{M} 1$ and $6 \mathrm{~N}-\mathrm{M} 2$ RNA aptamer that bound to PAP (lanes 4 and 6 ) were $59.2 \%, 54.7 \%$, respectively. These results suggest that a 50 nucleotide sequence and the Y-shaped structure (Fig. 6B, 6N-M2) may be essential for PAP binding.

The 5'-end of the 6N-M2 aptamer was biotinylated to confirm the PAP-specific binding. Subsequently, an in vitro competition assay was performed using the B-6N-M2 2'-FY RNA aptamer. Unlabeled library 2'-FY RNA and the 6N-M2 aptamer served as competitors. Increasing amounts of unlabeled $6 \mathrm{~N}-\mathrm{M} 2$ aptamer $(0,1,2,5$ and 10-fold excess competitor over the B-6N-M2 2'FY RNA aptamer) effectively disrupted the B-6N-M2 2'-FY RNA aptamer-PAP interaction in a dose-dependent manner (Fig. 6D, lanes 2 and 7-10). However, unlabeled library 2'-FY RNA (0, 1, 2,5 , and 10-fold excess of competitor over B-6N-M2 2'-FY 
A

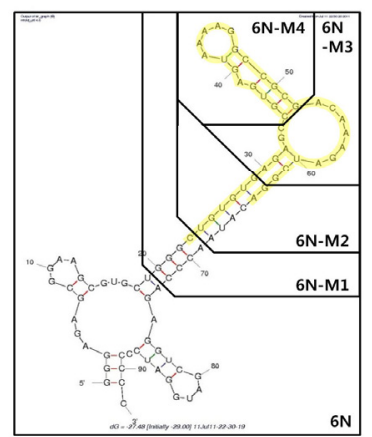

C

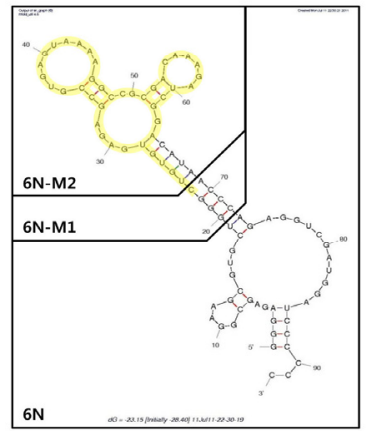

B
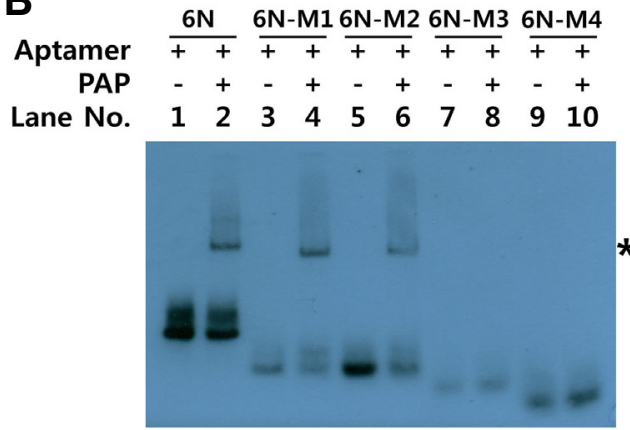

D

B-6N-M2 aptamer ++++++++++

PAP - ++++++++

Library - - - -

6N-M2 aptamer - - $-5-2$

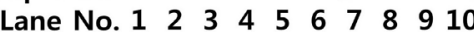

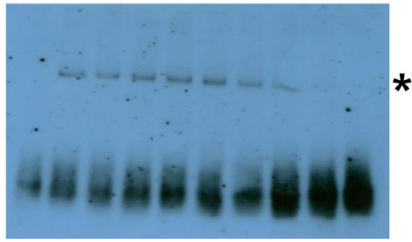

Fig. 6. Minimizing the 6N 2'-FY RNA aptamer without loss of its target binding capability. (A, B) Predicted secondary structure of the $6 \mathrm{~N} 2$ 'FY RNA aptamer by Mfold program. Two possible $6 \mathrm{~N}$ RNA aptamer structures are shown (6N). 6N-M1 and 6N-M2 can form L-shaped (A, $6 \mathrm{~N}-\mathrm{M} 1$, and $6 \mathrm{~N}-\mathrm{M} 2)$ and $\mathrm{Y}$-shaped (B, 6N-M1, and $6 \mathrm{~N}-\mathrm{M} 2$ ) structures. $6 \mathrm{~N}-\mathrm{M} 3$ maintains only an L-shaped structure (A, 6N-M3) and 6N-M4 is the shortest hairpin structure in $(A)$. (C) The EMSA was performed to demonstrate the binding capability of the minimized $6 \mathrm{~N} 22^{\prime}-\mathrm{FY}$ RNA aptamer against PAP. The 6N-M1 2'-FY RNA aptamer and the 6N-M2 2'-FY RNA aptamer bound to PAP (lanes 4 and 6) as strongly as that of the $6 \mathrm{~N} \mathrm{2}$ '-FY RNA aptamer (lane 2). However, the 6N-M3 2'-FY RNA aptamer and the 6N-M4 2'-FY RNA aptamer lost binding capability (lanes 8 and 10). (D) A competition binding assay was used to confirm 6N-M2 2'FY RNA aptamer binding specificity. The $6 \mathrm{~N}$ M2 2'-FY RNA aptamer competitively bound to PAP. The unlabeled library RNA (Library) did not affect binding of the biotinylated $6 \mathrm{~N}-\mathrm{M} 22^{\prime}-$ FY RNA aptamer (B-6N-M2 aptamer, lanes 36 , hot:cold $=1: 1,2,5$ and 10 , respectively). However, the unlabeled 6N-M2 2'-FY RNA aptamer (6N-M2 aptamer) competitively dis-

rupted the B-6N-M2 2'-FY RNA aptamer-PAP interaction (lanes 7-10, hot:cold = 1:1, 2, 5 and 10, respectively). The B-6N-M2 2'-FY RNA aptamer:PAP ratio was 1:200 (lanes 2-10).

A

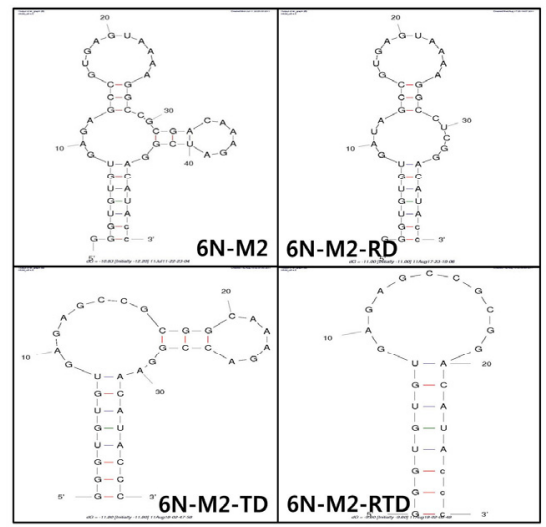

B

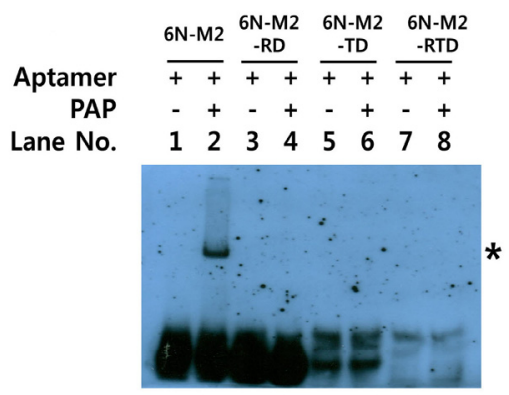

Fig. 7. Two hairpin structures in the 6N-M2 2'FY RNA aptamer appear to be important for PAP binding. Truncated versions of the $6 \mathrm{~N}-\mathrm{M} 2$ 2'-FY RNA aptamer were generated to examine the role of each hairpin structure in the 6N-M2 2'-FY RNA aptamer important for PAP binding. (A) Structures of truncated versions of 6N-M2 2'-FY RNA aptamer. The 6N-M2 2'-FY RNA aptamer had a Y-shaped structure (lane 1, 6N-M2). Predicted structures of right-, top-, and right and top deleted versions are depicted (6N-M2-RD, 6N-M2-TD, and 6N-M2-RTD, respectively). (B) No RNA aptamer-PAP interaction was observed in the truncated versions (lanes 4, 6, and 8).
RNA aptamer) did not inhibit the interaction (Fig. 6D, lanes 2-6). These results demonstrate that the $6 \mathrm{~N}-\mathrm{M} 2$ aptamer binds specifically to PAP.

The intact Y-shaped hairpin structure appears to be important for PAP binding

To examine in more detail which hairpin structure is important for binding in the minimized 6N 2'-FY RNA aptamer, 6N-M2 aptamer were further truncated to give 3 deletion versions: deletion of right hairpin structure (Fig. 7A, 6N-M2-RD), deletion of top hairpin structure (Fig. 7A, 6N-M2-TD), and deletion of both hairpin structures (Fig. 7A, 6N-M2-RTD). Gel shift assay results showed that all truncated versions of $6 \mathrm{~N}-\mathrm{M} 2$ aptamer did not bind to PAP (Fig. 7B, lane 4, 6 and 8). This result suggests that these two hairpin structures may be essential for PAP binding and that they might directly interact with PAP.

\section{DISCUSSION}

In this study, we report for the first time that a 2'-FY modified RNA aptamer can bind to human prostatic acid phosphatase (PAP) with a Kd value of $118 \mathrm{nM}$. This aptamer specifically bound to PAP-expressing prostate cancer (PC) cell lines and was successfully minimized without impairing its target binding capability. 
Systematic truncation studies suggested that two hairpin structures within a 50 nucleotide sequence were important for PAP binding. Despite the need for further validation of PAP specificity of the aptamer, including super-shift analyses with PAPspecific antibodies or aptamer-based PAP immunoprecipitation, our 6N 2'-FY RNA aptamer should be useful for many PC studies as well as prognosis of PC and therapeutic applications.

PAP is as an important prognostic marker for PC because its level increases proportionally during PC progression, and this correlation is consistent with the morphological characteristics of $\mathrm{PC}$ and is significantly higher than that of other PC biomarkers (Gunia et al., 2009; Madu and Lu, 2010). Moreover, PAP concentration is also correlated with cause-specific survival (Fang et al., 2008). These features are important because enhanced clinical predictions are increasingly needed, and the oncology field strives to improve clinical success rates. On the other hand, PAP belongs to a non-specific tyrosine phosphatase group (Hassan et al., 2010) and an authentic tyrosine phosphatase called cellular PAP functions as a negative growth regulator in PC cells (Chuang et al., 2010; Greene et al., 2013) Due to its dephosphorylation activity, RAF1 and PI3K signalings are also inhibited, which leads to decreased prostate cell proliferation and survival, resulting in reduced tumorigenicity (Lin et al., 1998; 2001). These seemingly somewhat contradictory results are due to the presence of different forms of PAP, such as cellular, secretory, and transmembrane PAPs. However, no way to effectively distinguish the PAP isoforms at the protein level is available and the regulatory mechanisms for differential expression remain unclear. Nevertheless, PAP is an important therapeutic target for $\mathrm{PC}$, as evidenced by the recent success of immunotherapy based on PAP. Provenge, which is based on PAP-charged autologous cells, has been FDAapproved and commercialized (Gerritsen 2012; Kong and Byun, 2013; Sims, 2012). Moreover, a PAP encoded DNA vaccine is currently undergoing clinical trials to prevent and treat PC (Lubaroff, 2012; McNeel et al., 2009)

An RNA aptamer is similar to an antibody with a wide range of target recognition sites and a variety of applications. However, RNA aptamers have key advantages over antibodies, such as tolerance to $\mathrm{pH} /$ temperatures that proteins cannot tolerate, low toxicity and immunogenicity, chemical modifications to improve yield, custom tailored properties, easier synthesis, and a small size, which can lead to more target binding and improved transport properties allowing cell-specific targeting and improved tissue penetration. Moreover, the effect of an RNA aptamer can be modulated or reversed by utilizing an anti-dote composed of the antisense-sequence (Bompiani et al., 2012). Many factors can affect RNA aptamer binding capability including the 2'-FY modification used in this study. Although 2'- substitution is the most common strategy to increase RNA stability in biological fluids, RNA structure and binding capability may be affected. Therefore, additional modifications of the selected aptamer must be considered seriously before it is used for the intended function. In contrast, just one nucleotide change (Fig. $1 \mathrm{C}$, clone 8 vs. clone 12) can lead to loss of binding capability, as demonstrated in Fig. 2.

Another caveat is that naivve human PAP has three glycosylation sites, which could affect PAP binding to the aptamer. We speculate that the PAP aptamer binding site may not contain these glycosylation sites. However, further biochemical binding studies are needed to resolve this issue. The technical difficulty at the present is that the $2^{\prime}-\mathrm{FY}$ modification precludes a foot printing assay, which is important to determine the RNA aptamer binding site. However, truncation studies of secondary structures to determine the PAP interaction site of the $6 \mathrm{~N}-\mathrm{M} 2$ RNA aptamer suggests that the two hairpin structures in the 6N-M2 RNA aptamer are equally important for target binding (Fig. 7). Moreover, as many RNA aptamers have functional characteristics (Jayasena, 1999; Ray and White, 2010), the antagonistic and agonistic functions of the 6N-M2 RNA aptamer must be investigated. If the PAP RNA aptamer has an antagonistic function, it can be developed for $\mathrm{PC}$ therapeutics in the same way as Macugen (Pegaptanib), which is the first FDA-approved aptamer drug that inhibits VEGF $_{165}$ (Rockey et al., 2011), was developed for age-related macular degeneration. In another application, non-functional RNA aptamers or neutral aptamers could be used as escort molecules by conjugation with other molecules, such as imaging probes, chemotherapeutics, siRNA, or photosensitizers. Further mechanistic studies including sophisticated minimizations are warranted for successful clinical applications of the PAP aptamer

In conclusion, a novel 2'-FY RNA aptamer against human PAP was screened successfully from an RNA library, and the selected aptamer specifically bind to PAP and PAP-expressing PC cells. Systematic minimization and deletion analyses of secondary structures revealed that a 50 nucleotide sequence and two hairpin structures were important for PAP aptamer binding capacity. This PAP aptamer should provide a novel platform on which other theragnostic molecules, such as anticancer drugs, imaging probes, and nanoparticles, can be conjugated. Despite the need for further characterization, our study opens up a new route for early theragnosis of PC.

Note: Supplementary information is available on the Molecules and Cells website (www.molcells.org).

\section{ACKNOWLEDGMENTS}

The present research was conducted by the research fund of Dankook University in 2012.

\section{REFERENCES}

Azumi, N., Traweek, S.T., and Battifora, H. (1991). Prostatic acid phosphatase in carcinoid tumors. Immunohistochemical and immunoblot studies. Am. J. Surg. Pathol. 15, 785-790.

Bompiani, K.M., Woodruff, R.S., Becker, R.C., Nimjee, S.M., and Sullenger, BA. (2012). Antidote control of aptamer therapeutics: the road to a safer class of drug agents. Curr. Pharm. Biotechnol. 13, 1924-1934.

Bruno, J.G., Carrillo, M.P., Phillips, T., Vail, N.K., and Hanson, D. (2008). Competitive FRET-aptamer-based detection of methylphosphonic acid, a common nerve agent metabolite. J. Fluoresc. 18, 867-876

Cary, K.C., and Cooperberg, M.R. (2013). Biomarkers in prostate cancer surveillance and screening : past, present, and future. Ther. Adv. Urol. 5, 318-329.

Chen, F., Hu, Y., Li, D., Chen, H., and Zhang, X.L. (2009) CSSELEX generates high-affinity ssDNA aptamers as molecular probes for hepatitis C virus envelope glycoprotein E2. PLoS One 4, e8142.

Chuang, T.D., Chen, S.J., Lin, F.F., Veeramani, S., Kumar, S., Batra, S.K., Tu, Y., and Lin, M.F. (2010). Human prostatic acid phosphatase, an authentic tyrosine phosphatase, dephosphorylates ErbB-2 and regulates prostate cancer cell growth. J. Biol. Chem. 285, 23598-23606.

Ellington, A.D., and Szostak, J.W. (1990). In vitro selection of RNA molecules that bind specific ligands. Nature 346, 818-822.

Eyetech Study Group. (2002). Preclinical and phase 1A clinical evaluation of an anti-VEGF pegylated aptamer (EYE001) for the treatment of exudative age-related macular degeneration. Retina 22, 143-152.

Fang, L.C., Dattoli, M., Taira, A., True, L., Sorace, R., and Wallner, 
K. (2008) Prostatic acid phosphatase adversely affects causespecific survival in patients with intermediate to high-risk prostate cancer treated with brachytherapy. Urology 71, 146-150.

Foy, J.W., Rittenhouse, K., Modi, M., and Patel, M. (2007). Local tolerance and systemic safety of pegaptanib sodium in the dog and rabbit. J. Ocul. Pharmacol. Ther. 23, 452-466.

Gerritsen, W.R. (2012). The evolving role of immunotherapy in prostate cancer. Ann. Oncol. 23, Suppl 8:viii22-27.

Gopinath, S.C. (2007). Methods developed for SELEX. Analytical and bioanalytical chemistry 387, 171-182

Greene, K.L., Albertsen, P.C., Babaian, R.J., Carter, H.B., Gann, P.H., Han, M., Kuban, D.A., Sartor, A.O., Stanford, J.L., Zietman, A., et al. (2013). Prostate specific antigen best practice statement: 2009 update. J. Urol. 189 (1 Suppl), S2-S11.

Gunia, S., Koch, S., May, M., Dietel, M., and Erbersdobler, A. (2009). Expression of prostatic acid phosphatase (PSAP) in transurethral resection specimens of the prostate is predictive of histopathologic tumor stage in subsequent radical prostatectomies. Virchows. Arch. 454, 573-579.

Hamula, C.L., Le, X.C., and Li, X.F. (2011). DNA aptamers binding to multiple prevalent M-types of Streptococcus pyogenes. Anal. Chem. 83, 3640-3647.

Hassan, M.I., Aijaz, A., and Ahmad, F. (2010). Structural and functional analysis of human prostatic acid phosphatase. Expert Rev. Anticancer Ther. 10, 1055-1068.

Hong, H., Goel, S., Zhang, Y., and Cai, W. (2011). Molecular imaging with nucleic acid aptamers. Curr. Med. Chem. 18, 41954205.

Jayasena, S.D. (1999). Aptamers: an emerging class of molecules that rival antibodies in diagnostics. Clin. Chem. 45, 1628-1650.

Kawakami, J., Imanaka, H., Yokota, Y., and Sugimoto, N. (2000). In vitro selection of aptamers that act with $\mathrm{Zn}^{2+}$. J. Inorg. Biochem. 82, 197-206

Kong, H.Y., and Byun, J. (2013). Emerging roles of human prostatic acid phosphatase. Biomol. Ther. 21, 10-20.

Lin, M.F., Meng, T.C., Rao, P.S., Chang, C., Schonthal, A.H., and Lin, F.F. (1998). Expression of human prostatic acid phosphatase correlates with androgen-stimulated cell proliferation in prostate cancer cell lines. J. Biol. Chem. 273, 5939-5947.

Lin, M.F., Lee, M.S., Zhou, X.W., Andressen, J.C., Meng, T.C., Johansson, S.L., West, W.W., Taylor, R.J., Anderson, J.R., and Lin, F.F. (2001). Decreased expression of cellular prostatic acid phosphatase increases tumorigenicity of human prostate cancer cells. J. Urol. 166, 1943-1950.

Liu, Z., Duan, J.H., Song, Y.M., Ma, J., Wang, F.D., Lu, X., and Yang, X.D. (2012). Novel HER2 aptamer selectively delivers cytotoxic drug to HER2-positive breast cancer cells in vitro. J. Transl. Med. 10:148

Lubaroff, D.M. (2012). Prostate cancer vaccines in clinical trials. Expert Rev. Vaccines 11, 857-868.

Madu, C.O., and Lu, Y. (2010). Novel diagnostic biomarkers for prostate cancer. J. Cancer 1, 150-177.

McNeel, D.G., Dunphy, E.J., Davies, J.G., Frye, T.P., Johnson, L.E., Staab, M.J., Horvath, D.L., Straus, J., Alberti, D., Marnocha, R., et al. (2009). Safety and immunological efficacy of a DNA vaccine encoding prostatic acid phosphatase in patients with stage D0 prostate cancer. J. Clin. Oncol. 27, 4047-4054.

Meng, L., Yang, L., Zhao, X., Zhang, L., Zhu, H., Liu, C., and Tan, W. (2012). Targeted delivery of chemotherapy agents using a liver cancer-specific aptamer. PLoS One 7, e33434.

Mosing, R.K., Mendonsa, S.D., and Bowser, M.T. (2005). Capillary electrophoresis-SELEX selection of aptamers with affinity for HIV-1 reverse transcriptase. Anal. Chem. 77, 6107-6112.

Oesterling, J.E., Suman, V.J., Zincke, H., and Bostwick, D.G. (1993). PSA-detected (clinical stage T1c or B0) prostate cancer. Pathologically significant tumors. Urol. Clin. North Am. 20, 687-693.

Ray, P., and White, R.R. (2010). Aptamers for targeted drug delivery. Pharmaceuticals 3, 1761-1778.

Reiter, R.J., Tan, D.X., Manchester, L.C., Korkmaz, A., FuentesBroto, L, Hardman, W.E., Rosales-Corral, S.A, and Qi, W. (2013). A walnut-enriched diet reduces the growth of LNCaP human prostate cancer xenografts in nude mice. Cancer Invest. 31, 365-373.

Rockey, W.M., Huang, L., Kloepping, K.C., Baumhover, N.J., Giangrande, P.H., and Schultz, M.K. (2011). Synthesis and radiolabeling of chelator-RNA aptamer bioconjugates with copper-
64 for targeted molecular imaging. Bioorg. Med. Chem. 19, 4080-4090.

Ruckman, J., Green, L.S., Beeson, J., Waugh, S., Gillette, W.L., Henninger, D.D., Claesson-Welsh, L., and Janjic, N. (1998). 2'Fluoropyrimidine RNA-based aptamers to the 165-amino acid form of vascular endothelial growth factor (VEGF165). Inhibition of receptor binding and VEGF-induced vascular permeability through interactions requiring the exon 7-encoded domain. $\mathrm{J}$. Biol. Chem. 273, 20556-20567.

Savla, R., Taratula, O., Garbuzenko, O., and Minko, T. (2011). Tumor targeted quantum dot-mucin 1 aptamer-doxorubicin conjugate for imaging and treatment of cancer. J. Control. Release $153,16-22$

Sims, R.B. (2012). Development of sipuleucel-T: autologous cellular immunotherapy for the treatment of metastatic castrate resistant prostate cancer. Vaccine 30, 4394-4397.

Soares, N.D. Teodoro, A.J., Oliveira, F.L Santos, C.A., Takiya, C.M., Junior, O.S., Bianco, M., Junior, A.P., Nasciutti, L.E., Ferreira, L.B., et al. (2013). Influence of lycopene on cell viability, cell cycle, and apoptosis of human prostate cancer and benign hyperplastic cells. Nutr. Cancer 65, 1076-1085

Song, Y., Zhu, Z., An, Y., Zhang, W., Zhang, H., Liu, D., Yu, C. Duan, W., and Yang, C.J. (2013). Selection of DNA aptamers against epithelial cell adhesion molecule for cancer cell imaging and circulating tumor cell capture. Anal. Chem. 85, 4141-4149.

Subramanian, N., Raghunathan, V., Kanwar, J.R., Kanwar, R.K., Elchuri, S.V., Khetan, V., and Krishnakumar, S. (2012). Targetspecific delivery of doxorubicin to retinoblastoma using epithelial cell adhesion molecule aptamer. Mol. Vis. 18, 2783-2795.

Taira, A., Merrick, G., Wallner, K., and Dattoli, M. (2007). Reviving the acid phosphatase test for prostate cancer. Oncology 21 , 1003-1010

Talbot, L.J., Mi, Z., Bhattacharya, S.D., Kim, V., Guo, H., and Kuo, P.C. (2011). Pharmacokinetic characterization of an RNA aptamer against osteopontin and demonstration of in vivo efficacy in reversing growth of human breast cancer cells. Surgery 150 224-230.

Tang, Z., Parekh, P., Turner, P., Moyer, R.W., and Tan, W. (2009). Generating aptamers for recognition of virus-infected cells. Clin. Chem. 55, 813-822.

Thompson, I.M., Pauler, D.K., Goodman, P.J., Tangen, C.M., Lucia, M.S., Parnes, H.L., Minasian, L.M., Ford, L.G., Lippman, S.M., Crawford, E.D., et al. (2004). Prevalence of prostate cancer among men with a prostate-specific antigen level $<$ or $=4.0 \mathrm{ng}$ per milliliter. N. Engl. J. Med. 350, 2239-2246.

Tuerk, C., and Gold, L. (1990). Systematic evolution of ligands by exponential enrichment: RNA ligands to bacteriophage T4 DNA polymerase. Science 249, 505-510.

Wallace, D.M., Chisholm, G.D., and Hendry, W.F. (1975). T.N.M. classification for urological tumours (U.I.C.C.) - 1974. Br. J. Urol. $47,1-12$.

Walter, L.C., Bertenthal, D., Lindquist, K., and Konety, B.R. (2006) PSA screening among elderly men with limited life expectancies. JAMA 296, 2336-2342.

Wang, Y., Harada, M., Yano, H., Ogasawara, S., Takedatsu, H., Arima, Y., Matsueda, S., Yamada, A., and Itoh, K. (2005). Prostatic acid phosphatase as a target molecule in specific immunotherapy for patients with nonprostate adenocarcinoma. J. Immunother. 28, 535-541.

Whitesel, J.A., Donohue, R.E., Mani, J.H., Mohr, S., Scanavino, D.J., Augspurger, R.R., Biber, R.J., Fauver, H.E., Wettlaufer, J.N., and Pfister, R.R. (1984). Acid phosphatase: its influence on the management of carcinoma of the prostate. J. Urol. 131, 7072.

Zhang, Y., Hong, H., and Cai, W. (2011). Tumor-targeted drug delivery with aptamers. Curr. Med. Chem. 18, 4185-4194.

Zhang, M.Z., Yu, R.N., Chen, J., Ma, Z.Y., and Zhao, Y.D. (2012). Targeted quantum dots fluorescence probes functionalized with aptamer and peptide for transferrin receptor on tumor cells. $\mathrm{Na}$ notechnology 23, 485104.

Zhu, G., Ye, M., Donovan, M.J., Song, E., Zhao, Z., and Tan, W. (2012). Nucleic acid aptamers: an emerging frontier in cancer therapy. Chem. Commun. 48, 10472-10480.

Zimmermann, H. (2009). Prostatic acid phosphatase, a neglected ectonucleotidase. Purinergic Signal 5, 273-275.

Zuker, M. (2003). Mfold web server for nucleic acid folding and hybridization prediction. Nucleic Acids Res. 31, 3406-3415. 